\title{
Resistant hypertension: a dangerous and challenging clinical situation
}

\begin{abstract}
High blood pressure is a very important risk factor for the development of Cardiovascular Diseases (CVD), which are among the main causes of death globally. In particular, Resistant Hypertension (RH) predisposes individuals to a higher risk of CVD. RH is defined as the absence of blood pressure control despite the use of at least three classes of antihypertensive agents, one of them being a diuretic, in optimal dosage. To identify true RH, it is essential to exclude specific clinic conditions, such as pseudo-resistance and causes of Secondary Hypertension (SR), since these situations can also be related to poorly controlled hypertension. A large number of factors may be investigated to exclude pseudoresistance, which includes: non-adherence to the antihypertensive therapy, white coat hypertension, inaccurate blood pressure measurement, non-optimized therapeutic scheme, low acceptance of the need for life-style modifications. In this review we will address the aspects of the pathophysiology, diagnosis and treatment of HR.
\end{abstract}

Keywords: resistant hypertension, blood pressure, secondary arterial hypertension, cardiovascular disease
Volume 4 Issue 5 - 2019

\author{
Nathássia Rodrigues Guedes,' Pedro \\ Henrique Resende Farina,' Guilherme \\ Silva, ${ }^{2}$ Leonardo Roever, ${ }^{3}$ Rodrigo Penha de \\ Almeida,' João Lucas O'Connell' \\ 'Department of Cardiology, Federal University of Uberlândia, \\ Brazil \\ ${ }^{2}$ Department of Internal Medicine, Faculty of Medicine, Federal \\ University of Minas Gerais, Brazil \\ ${ }^{3}$ Department of Clinical Research, Federal University of \\ Uberlândia, Brazil \\ Correspondence: João Lucas O'Connell, Department of
Cardiology, Federal University of Uberlândia, Brazil \\ Tel 55349665-I I59, Email oconnellj|@icloud.com
}

Received: October 06, 2019| Published: October 21, 2019
Abbreviations: CVD, cardiovascular diseases; CCB, calcium channel blocker; SR, secondary hypertension; ABPM, ambulatory blood pressure monitoring; PA, primary aldosteronism, OSA, Obstructive sleep apnea; RD, renovascular disease; RPD, renal parenchymal disease

\section{Introduction}

High blood pressure is a very important risk factor for the development of Cardiovascular Diseases (CVD), which are among the main causes of death globally. ${ }^{1}$ In particular, Resistant Hypertension $(\mathrm{RH})$ predisposes individuals to a higher risk of CVD. $\mathrm{RH}$ is defined as the absence of blood pressure control despite the use of at least three classes of antihypertensive agents, one of them being a diuretic (when tolerated), in optimal dosage. The higher vulnerability presented by this group of patients is due to the prolonged period of uncontrolled hypertension and to the coexistence of other risk factors, such as obesity, diabetes and dyslipidemia. ${ }^{2}$ It is valid to emphasize that this definition of RH also extends to those patients which require at least four classes of antihypertensive drugs to maintain normal blood pressure levels. $^{3-5}$

Frequently, the term "refractory hypertension" is used as a synonym of RH, however it corresponds to a clinical condition with worse prognosis when compared to RH and therefore is related to even greater complications. It is defined as failure to control blood pressure despite the use of at least 5 different classes of antihypertensive agents, including a long-acting thiazide-type diuretic and a mineralocorticoid receptor antagonist. ${ }^{5,6}$

Ideally, the triple therapeutic scheme is composed of a reninangiotensin system blocker (an angiotensin-converting enzyme inhibitor-ACE inhibitor; or an angiotensin receptor blocker-ARB), a calcium channel blocker (CCB) and a diuretic. ${ }^{3-5}$ In patients with preserved or slightly diminished renal function, it is preferable to use chlorthalidone or indapamide rather than hydrochlorothiazide, since they're more potent agents, in part due to its longer action time. ${ }^{7,8}$

To identify true RH, it is essential to exclude specific clinic conditions, such as pseudo-resistance and causes of Secondary Hypertension (SR), since these situations can also be related to poorly controlled hypertension. ${ }^{9}$ A large number of factors may be investigated to exclude pseudo-resistance, which includes: nonadherence to the antihypertensive therapy, white coat hypertension, inaccurate blood pressure measurement, non-optimized therapeutic scheme, low acceptance of life-style modifications (physical activity, smoking and alcoholism cessation, and low sodium ingestion). ${ }^{4,6}$

In relation to $\mathrm{SH}$, it is fundamental to investigate the disorders that are more commonly associated with this condition: Obstructive Sleep Apnea; Renovascular Disease; Primary Aldosteronism and Renal Parenchymal Disease. However, it should be noted that other more uncommon causes must be remembered when facing antihypertensive drug resistance, such as Pheochromocytoma, Cushing's syndrome, Thyroid Diseases and Hyperparathyroidism. There are also medications that can contribute to an increase in arterial blood pressure and to the development of RH, but the manifestation of these effects is individual to each patient, and some of them may not present blood pressure alterations when using them. ${ }^{10}$

The aim of this review is to describe the complexity of RH and its peculiarities, and to determine the main tools that should be used to the adequate diagnosis and to establish an effective therapy, not only to improve the patient condition, but also to prevent future complications which these individuals are predisposed to. 


\section{Methods}

\section{Literature search strategy}

We undertook a systematic search of EMBASE (http://www. embase.com) and Pub Med (http://www.ncbi.nlm.nih.gov/pubmed) through August 2019 for studies related to RH and CVD. The following search terms were entered in the database searches: resistant hypertension, diagnosis, evaluation, and treatment. In addition, Reference lists of all relevant articles and identified reviews were inspected to identify pertinent articles that could have been missed in the initial search.

\section{Diagnosis}

Clinical history and physical examination: Clinical history and physical examination should be performed in order to confirm the diagnosis of RH and to evaluate the best therapeutic scheme available, considering the adequate choice of the available medications and the blood pressure goals to be achieved. The existence of clinical entities that also contribute to the poorly controlled hypertension should be investigated, such as pseudo-resistance (non-adherence, non-optimized therapeutic schemes, inadequate life habits, white coat hypertension and inaccurate blood pressure measurement). We also have to evaluate if there is already established target organ damage. It is also important to identify the medications in use by the patient, some of them which may cause blood pressure elevations. In many clinical scenarios, the resistance to the established treatment is due to multiple etiologies, which must be properly identified and managed. ${ }^{3,10}$ Table 1 shows several medications that can interfere with blood pressure control.

Table I Medications that can interfere with blood pressure control

Nonnarcotic analgesics
Nonsteroidal anti-inflammatory agents, including aspirin
Selective COX-2 inhibitors
Sympathomimetic agents (decongestants, diet pills, cocaine
Stimulants (methylphenidate, dexmethylphenidate, dextroamphetamine,
amphetamine, methamphetamine, modafinil
Alcohol
Oral contraceptives
Cyclosporine
Erythropoietin
Natural licorice
Herbal compounds (ephedra or ma huang)

Data form ${ }^{10}$

\section{Measurement of blood pressure}

In the office: Applying the adequate technique to measure blood pressure is indispensable in $\mathrm{RH}$ investigation, considering it is one of the requirements to rule-out pseudo-resistance. Among the requirements recommended to the accurate blood pressure measurement, it is mostly important that: the patient stays at least 5 minutes sitting on a chair, in a calm environment; the cuff used has an adequate size; the patient's arm is positioned at the level of the heart; and that at least two readings are obtained within a one-minute interval, from which an average is obtained. ${ }^{10,11}$ The blood pressure should be measured in both arms, and the higher reading should be used as reference10. In relation to the patient positioning, it should ideally be seated, with the legs uncrossed, the feet on the floor, and the back supported in the chair3. However, during treatment, the patients should also be evaluated while lying in bed and in orthostatic position, so that orthostatic complications related to treatment can be identified. ${ }^{10}$

Ambulatory blood pressure monitoring and home blood pressure monitoring: Although the suspicion of RH can be made in the office evaluation through the finding of high blood pressure despite the use of, at least, three antihypertensive agents, one of them being a diuretic (if tolerated), in optimal dosage; the use of out-of-office monitoring is mandatory for diagnosis confirmation as well to establish management. ${ }^{10,12,14}$

The ambulatory blood pressure monitoring (ABPM) is considered the gold-standard for the determination of blood pressure values. ${ }^{15-18}$ This method allows a considerable amount of readings, which includes measurements performed during night-time; also, it ensures the absence of observer bias and helps diagnosing white coat hypertension. ${ }^{19,20}$ ABPM is considered the best predictor of cardiovascular morbimortality for high blood pressure patients. ${ }^{21}$ However, the efficacy of this technique can be limited by some factors, such as the cuff size, patient movement and corporal position, short term blood pressure variation, and sleep interference. ${ }^{22}$

In situations of low tolerance to ABPM (sleep and labor interference), home blood pressure monitoring (HBPM) can be used, however it is important to emphasize that this technique has some limitations when compared to $\mathrm{ABPM},{ }^{23}$ being characterized with high specificity and low sensibility13. HBPM does not ensure effective night-time evaluation-the period in which the blood pressure is more predictive of cardiovascular events, ${ }^{24}$ which also means the inability of this method to diagnose isolated nocturnal hypertension (which has the same cardiovascular risk as an altered ABPM) ${ }^{25} \mathrm{HBPM}$ is also not able to detect masked and sustained hypertension (high cardiovascular risk diseases) in more than $25 \%$ of patients. ${ }^{12}$ Table 2 describes the blood pressure limits for the diagnosis of arterial hypertension, based on different International Cardiology Societies Guidelines the for the management of arterial hypertension (Tables 3-5).

Table 2 Definitions of hypertension according to office, ambulatory, and home blood pressure levels according to the ESC/ESH Guidelines

\begin{tabular}{|c|c|c|c|}
\hline \multirow{2}{*}{$\begin{array}{l}\text { Category } \\
\text { Office BPI }\end{array}$} & \multicolumn{2}{|c|}{ SBP (mmHg) } & \multirow{2}{*}{$\begin{array}{l}\text { DBP }(\mathbf{m m H g}) \\
\geq 90\end{array}$} \\
\hline & $\geq 140$ & and/or & \\
\hline \multicolumn{4}{|l|}{ Ambulatory BP } \\
\hline Daytime (or awake) mean & $\geq 135$ & and/or & $\geq 85$ \\
\hline Night-time (or asleep) mean & $\geq 120$ & and/or & $\geq 70$ \\
\hline $24 \mathrm{~h}$ mean & $\geq 130$ & and/or & $\geq 80$ \\
\hline Home BP mean & $\geq 135$ & and/or & $\geq 85$ \\
\hline
\end{tabular}

$B P$, blood pressure; DBP, diastolic blood pressure; SBP, systolic blood pressure Refers to conventional office BP rather than unattended office BP

Data form ${ }^{30}$ 
Table 3 Definitions of hypertension according to office, ambulatory, and home blood pressure levels according to the Brazilian guidelines

\begin{tabular}{llll} 
Category & \multicolumn{2}{l}{ SBP $(\mathbf{m m H g})$} & DBP $(\mathbf{m m H g})$ \\
\hline Office BP & $\geq 140$ & and $/$ or & $\geq 90$ \\
AMBP & & & \\
Awake & $\geq 135$ & and $/$ or & $\geq 85$ \\
Asleep & $\geq 120$ & and $/$ or & $\geq 70$ \\
24 h mean & $\geq 130$ & and $/$ or & $\geq 80$ \\
HMBP & $\geq 135$ & and/or & $\geq 85$
\end{tabular}

BP, blood pressure; DBP, diastolic blood pressure; SBP, systolic blood pressure Data form ${ }^{39}$

Table 4 Definitions of hypertension according to office blood pressure levels according to the American Guidelines

\begin{tabular}{llll}
\hline BP Category & SBP & & DBP \\
\hline Normal & $<120 \mathrm{mmHg}$ & and & $<80 \mathrm{mmHg}$ \\
Elevated & $120-129 \mathrm{mmHg}$ & and & $<80 \mathrm{mmHg}$ \\
\hline Hypertension & & & \\
\hline Stage I & $130-139 \mathrm{mmHg}$ & or & $80-89 \mathrm{mmHg}$ \\
\hline Stage 2 & $\geq 140 \mathrm{mmHg}$ & or & $\geq 90 \mathrm{mmHg}$ \\
\hline
\end{tabular}

Dataform ${ }^{5}$

Table 5 Corresponding values of SBP/DBP for clinic, HBPM, daytime, nighttime, and 24-hour ABPM measurements

\begin{tabular}{lllll}
\hline Clinic & HBPM & $\begin{array}{l}\text { Daytime } \\
\text { ABPM }\end{array}$ & $\begin{array}{l}\text { Nighttime } \\
\text { ABPM }\end{array}$ & $\begin{array}{l}\text { 24-Hour } \\
\text { ABPM }\end{array}$ \\
\hline $120 / 80 \mathrm{mmHg}$ & $120 / 80 \mathrm{mmHg}$ & $120 / 80 \mathrm{mmHg}$ & $100 / 65 \mathrm{mmHg}$ & $115 / 75 \mathrm{mmHg}$ \\
$130 / 80 \mathrm{mmHg}$ & $130 / 80 \mathrm{mmHg}$ & $130 / 80 \mathrm{mmHg}$ & $110 / 65 \mathrm{mmHg}$ & $126 / 75 \mathrm{mmHg}$ \\
$140 / 90 \mathrm{mmHg}$ & $135 / 85 \mathrm{mmHg}$ & $135 / 85 \mathrm{mmHg}$ & $120 / 70 \mathrm{mmHg}$ & $130 / 80 \mathrm{mmHg}$
\end{tabular}

$A B P M$, indicates ambulatory blood pressure monitoring; $B P$, blood pressure; DBP, diastolic blood pressure; HBPM, home blood pressure monitoring; SBP, systolic blood pressure

Dataform $^{30}$

\section{Adherence to pharmacological treatment}

Therapeutic nonadherence is an important factor to be evaluated when facing RH suspicion, since the drugs used to treat hypertension cannot be effective if not taken in the correct posology. ${ }^{26,27}$

The indirect strategies to verify patient adherence to treatment, such as counting the number of pills used and asking patients about difficulties with the prescription (collateral effects and costs) are useful, but are prone to misconception and can result in diagnostic error. ${ }^{23}$

The gold-standard methods for the evaluation of therapeutic adherence are: the witnessed use of the medication ${ }^{28}$ and the direct or indirect measurement of drug concentrations in corporal fluids (blood and urine). ${ }^{29}$ However, even though the dosing of drug metabolites can establish if the medication is present or not in the patient's body, it cannot determine if the medication regimen was properly followed. ${ }^{3}$

Thus, it is noted that both the indirect methods as well as the direct methods have limitations and can result in diagnostic error. Therefore, it is important that a combination of these methods is used the medical approach, so that higher sensitivity and specificity are obtained. Besides that, it is also necessary that this analysis is carried out on all medical consultations. For being a process related to the interference of multiple psycho-social agents, the therapeutic adherence is a dynamic event and, thus, cannot be investigated in a single encounter. ${ }^{23}$

\section{Exclusion of secondary causes}

Secondary hypertension can be identified in about $10 \%$ of the patients with high blood pressure, and is defined by the presence of identifiable causes of blood pressure elevation, that can be diagnosed and treated. The specific approach to these alterations can result in a marked improvement in blood pressure control and in some cases, it is also possible to achieve cure of the underlying condition, provided that the intervention was made early in the diagnosis.,

\section{Obstructive sleep apnea (OSA)}

Obstructive Sleep Apnea has a prevalence of about $25-50 \%$ in patients with hypertension ${ }^{30}$ and is a common sleep disorder defined by the chronic collapse of upper airways during sleep, with resulting episodes of apnea or hypopnea. ${ }^{31}$ The hypoxemia caused by the respiratory dysfunction results in systemic endothelial dysfunction as well as intensification of the activity of the sympathetic nervous system and the renin-angiotensin system (RAS), which together cause vasoconstriction in several body regions. The activation of RAS is also related with sodium and water retention, which results in intravascular volume expansion and, as consequence, elevation of blood pressure levels. ${ }^{32-34}$

The patients with this condition have a phenotype characterized by obesity, large neck and macroglossia. The presence of symptoms is frequent, such as daytime sleepiness, irritability, difficulty to concentrate and snoring. ${ }^{4,30,35}$ Thus, when the presence of OSA is suspected, screening tests such as the Epworth Sleepiness Score and the Berlin Questionnaire should be performed. If necessary, the diagnosis of this clinical situation can also be confirmed by polysomnography. $4,30,36,37$

\section{Renovascular disease}

Renovascular Disease (RD), with a prevalence of $5-34 \%^{30}$ is a result of renal artery stenosis (uni or bilateral). The main etiologies of renal artery stenosis are atherosclerotic disease (more common in adult patients), fibromuscular dysplasia (more common in children and young adults), and less frequently Takayasu's arteritis. About $90 \%$ of the cases of renal artery stenosis are caused by atherosclerotic disease. ${ }^{38-40}$ The narrowing of the renal artery results in decreased renal blood flow and by consequence, pathologic activation of the RAS, causing abnormal blood pressure elevation. ${ }^{38}$

The RD of atherosclerotic origin represents about $90 \%$ of the diagnosed cases, being the most common cause. Advanced age, diabetes, smoking, diffuse atherosclerosis, recurrent pulmonary edema, worsening of the renal function when starting ACE inhibitors or ARBs, and abdominal bruising are among the main features that suggest this condition. The occurrence of fibromuscular dysplasia is more common in women and abdominal bruises are also common in this clinical settin. $4,5,30,41$

After clinical suspicion, the renal arteries evaluation can be done by renal duplex Doppler ultrasound, abdominal computed tomography or 
by magnetic resonance. In cases which there is evidence of narrowing or in uncertain cases, it is recommended to perform a renal artery angiography, considered the gold-standard for the diagnosis. ${ }^{4,30}$

\section{Primary aldosteronism}

Primary Aldosteronism (PA), with a prevalence of $8-20 \% 30$ is a disorder characterized by high production of aldosterone, occurring in an inappropriate manner and relatively autonomous of the regulatory mechanisms, such as the RAS. The excessive production of aldosterone increases sodium and water reabsorption in the kidneys, and also creates an electric gradient that favors potassium secretion into the luminal space. There is also inhibition of the plasmatic renin activity. As a result, there is an intravascular volume expansion, with promotes elevations in blood pressure. Among the main causes of this disorder, are the aldosterone-producing adenoma and the adrenal hyperplasia. $^{42}$

In most of the cases patients present asymptomatic and, when present, symptoms are non-specific. The main clinical features include fatigue, asthenia, polyuria, polydipsia, intestinal constipation, headaches and palpitations. Hypokalemia can be present in less than half of the cases. ${ }^{4,43}$

The screening for this condition is done by plasmatic aldosterone dosing, plasmatic renin activity and primarily by the ration between these two parameters. ${ }^{44}$ To perform the dosing of these markers, the serum levels of potassium should be normal and the use of mineralocorticoid receptor antagonists should be suspended for at least four weeks. When the diagnosis is probable, in most of the cases it is necessary to perform confirmatory tests, and the most commonly used are the oral sodium loading test and the intravenous saline infusion test. The computed tomography of the adrenal glands is the test of choice for the identification of the disease subtype and to guide management. ${ }^{41,42,45}$

\section{Renal parenchymal disease}

Renal Parenchymal Disease, with a prevalence of $1-2 \% 30$ is a significant cause of secondary hypertension in children. ${ }^{46}$ Alterations in the renal parenchyma promote a renal function unbalance, resulting in intravascular volume expansion and in an exacerbation of vasoconstriction, which are responsible for elevations in blood pressure. $^{47,48}$

In several cases, patients are asymptomatic. However, the presence of diabetes, urinary changes, anemia, and urinary tract changes can suggest the existence of disease of the renal parenchyma. If there is clinical suspicion, the urinary analysis and the albumin/creatinin ration are the main methods of screening for this condition. Renal ultrasonography can also be used in this investigation., ${ }^{4,30}$ Finally, there are several other less common causes of secondary hypertension (Table 6).

Although it is apparently easy to recognize RH, its prevalence is still not well determined, in part due to the difficulty in making a reliable diagnosis, mainly when it is necessary to exclude pseudoresistance (nonadherence and suboptimal therapy). ${ }^{6}$ However, it is necessary to emphasize the importance of the medical ability in recognizing true $\mathrm{RH}$, since the patients considered resistant to the antihypertensive therapy have higher risks for the development of end organ damage and adverse outcomes (such as myocardial infarction, stroke, heart failure and chronic kidney disease). ${ }^{4-52}$
In conclusion, early identification of these patients allows medical professionals to establish more directed and aggressive therapeutics, when compared to the strategies aimed to patients classified as "good responders". With the better understanding of all the above aspects involved with RH, unfavorable outcomes could be avoided and a better life quality could be ensured for patients suffering from this dangerous clinical setting.

Table 6 Other causes of secondary hypertension

\begin{tabular}{|c|c|c|c|}
\hline Cause & Prevalence & $\begin{array}{l}\text { History and clinical } \\
\text { findings }\end{array}$ & $\begin{array}{l}\text { Screening } \\
\text { investigations }\end{array}$ \\
\hline Phaeochromocytoma & $0,1-0,6 \%$ & $\begin{array}{l}\text { Episodic symptoms } \\
\text { (the } 5 \text { “P's"): } \\
\text { paroxysmal } \\
\text { hypertension, } \\
\text { pounding headache, } \\
\text { perspiration, } \\
\text { palpitations, and } \\
\text { pallor;Also common: } \\
\text { anxiety, orthostatic } \\
\text { hypotension, labile } \\
\text { BP, BP surges } \\
\text { precipitated by drugs } \\
\text { (e.g. beta-blockers, } \\
\text { sympathomimetics, } \\
\text { opioids and tricyclic } \\
\text { antidepressants), } \\
\text { positive family } \\
\text { history of } \\
\text { pheochromocytoma. }\end{array}$ & $\begin{array}{l}\text { 24-h urinary } \\
\text { fractionated } \\
\text { metanephrines } \\
\text { or plasma } \\
\text { metanephrines. }\end{array}$ \\
\hline Cushing's syndrome & $<0,1 \%$ & $\begin{array}{l}\text { Moon face, central } \\
\text { obesity, skin atrophy, } \\
\text { hirsutism, impotence, } \\
\text { fatigue, psychological } \\
\text { changes, polydipsia, } \\
\text { polyuria and chronic } \\
\text { steroid use. }\end{array}$ & $\begin{array}{l}24 \text { h urinary } \\
\text { cortisol, } \\
\text { dexamethasone } \\
\text { testing. }\end{array}$ \\
\hline $\begin{array}{l}\text { Thyroid disease } \\
\text { (hyper - or } \\
\text { hypothyroidism }\end{array}$ & $<1 \%$ & $\begin{array}{l}\text { Hyperthyroidism: } \\
\text { palpitations, } \\
\text { accentuated heart } \\
\text { sounds, exophthalmia, } \\
\text { weight loss, anxiety, } \\
\text { heat intolerance; } \\
\text { Hypothyroidism: } \\
\text { weight gain, fatigue, } \\
\text { obstipation, cold } \\
\text { intolerance, } \\
\text { hoarseness, } \\
\text { bradycardia, } \\
\text { myxedema, }\end{array}$ & $\begin{array}{l}\text { Thyroid- } \\
\text { stimulating } \\
\text { Hormone, Free } \\
\text { Thyroxine. }\end{array}$ \\
\hline Hyperparathyroidism & Rare & $\begin{array}{l}\text { Hypercalcemia, } \\
\text { hypophosphatasemia. }\end{array}$ & $\begin{array}{l}\text { Parathyroid } \\
\text { hormone, } \mathrm{Ca}^{2}+\text {. }\end{array}$ \\
\hline
\end{tabular}

Dataform ${ }^{4,5,35}$

\section{Compliance with ethics guidelines}

\section{Human and animal rights and informed consent}

This article does not contain any studies with human or animal subjects performed by any of the author's.

\section{Acknowledgments}

None.

\section{Conflicts of interest}

All authors declare that they have no conflicts of interest. 


\section{References}

1. Gakidou, Emmanuela, et al. Global, regional, and national comparative risk assessment of 84 behavioural, environmental and occupational, and metabolic risks or clusters of risks, 1990-2016: a systematic analysis for the global burden of disease study 2016. The Lancet. 2018;390:1345-1422,

2. https://www.uptodate.com/contents/treatment-of-resistant-hypertension

3. Carey RM, George L, Robert D, et al. Resistant hypertension: detection evaluation, and management. Hypertension. 2018;72(5):53-90.

4. Williams B, Giuseppe M, Wilko S, et al. 2018 ESC/ESH guidelines for the management of arterial hypertension. European Heart Journal, 2018;39(33):3021-3104.

5. Whelton PK, Robert MK, Wilbert SA, et al. 2017 ACC/AHA/AAPA/ $\mathrm{ABC} / \mathrm{ACPM} / \mathrm{AGS} / \mathrm{APhA} / \mathrm{ASH} / \mathrm{ASPC} \mathrm{NMA} / \mathrm{PCNA}$ guideline for the prevention, detection, evaluation, and management of high blood pressure in adults: a report of the american college of cardiology/american heart association task force on clinical practice guidelines. Hypertension. 2018;71(6):13-115.

6. Calhoun AD, Townsend, Raymond R. Definition, risk factors, and evaluation of resistant hypertension. 2019.

7. Agarwal R, Sinha AD, Pappas MK, et al. Chlorthalidone for poorly controlled hypertension in chronic kidney disease: an interventional pilot study. American Journal of Nephrology. 2014;39(2):171-182.

8. Sica, Domenic A..Chlorthalidone. Hypertension. 2006;47(3):321-322.

9. Sarafidis PA, Georgianos P, Bakris GL. Resistant hypertensionits identification and epidemiology. Nature Reviews Nephrology. 2012;9(1):51-58.

10. Calhoun DA, Jones D, Textor S, et al. Resistant hypertension: diagnosis, evaluation and treatment. Circulation. 2008;117(25):510-526.

11. Pickering TG, Hall JE, Appel LJ, et al. Recommendations for blood pressure measurement in humans and experimental animals. Circulation. 2005;111(5):697-716.

12. de la Sierra A1, Segura J, Banegas JR, et al. Clinical features of 8295 patients with resistant hypertension classified on the basis of ambulatory blood pressure monitoring. Hypertension. 2011;57(5):898-902.

13. Muxfeldt ES, Barros GS, Viegas BB,. et al. Is Home blood pressure monitoring useful in the management of patients with resistant hypertension?. American Journal of Hypertension. 2014;28(2):190-199.

14. Muxfeldt ES, Salles GF. How to use ambulatory blood pressure monitoring in resistant hypertension. Hypertension Research. 2013;36(5):385-389.

15. Leung AA, Nerenberg K, Daskalopoulou SS. et al. Hypertension canada's 2016 canadian hypertension education program guidelines for blood pressure measurement, diagnosis, assessment of risk, prevention, and treatment of hypertension. Canadian Journal Oof Cardiology. 2016;32(5):569-588.

16. O’Brien E, Parati G, Stergiou G, et al. European society of hypertension position paper on ambulatory blood pressure monitoring. Journal of Hypertension. 2013;31(9):1731-1768.

17. Siu AL. Screening for high blood pressure in adults: U.S. preventive services task force recommendation statement. Annals of Internal Medicine. 2015;163(10):778-786.

18. The national institute for health and care excellence. Hypertension in adults: diagnosis and management. The National Institute For Health And Care Excellence. England. 2011;1-25.

19. O'Brien, Roland A, Lawrie B, et al. European society of hypertension recommendations for conventional, ambulatory and home blood pressure measurement. Journal of Hypertension. 2003;21(5):821-848.
20. Eoin O'Brien, Roland Asmar, Lawrie Beilin, et al. Practice guidelines of the european society of hypertension for clinic, ambulatory and self blood pressure measurement. Journal of Hypertension. 2004;23(4):697-701.

21. James PA, Suzanne O, Barry LC, et al. 2014 Evidence-based guideline for the management of high blood pressure in adults. Jama. 2014;311(5):507521 .

22. Staessen JA, Fagard R, Thijs L, et al. A consensus view on the technique of ambulatory blood pressure monitoring. The fourth international consensus conference on 24-hour ambulatory blood pressure monitoring. Hypertension. 1995;26(6 Pt 1):912-918.

23. Wei FF, Zhang ZY, Huang QF, et al. Diagnosis and management of resistant hypertension: state of the art. Nat Rev Nephrol. 2018;14(7):428-441.

24. Boggia J, Li Y, Thijs L, Hansen TW, et al. Prognostic accuracy of day versus night ambulatory blood pressure: a cohort study. The Lancet. 2007;370(9594):1219-1229.

25. Staessen JA, O'Brien ET, Amery AK, et al. Ambulatory blood pressure in normotensive and hypertensive subjects: results from an international database. J Hypertens Suppl. 1994;12(7):S1-12.

26. Burnier M, Wuerzner G, Struijker-Boudier H, et al. Measuring, analyzing, and managing drug adherence in resistant hypertension. Hypertension. 2013 Aug;62(2):218-225.

27. Gifford Junior, Ray W. An algorithm for the management of resistant hypertension. 2019.

28. Elmula EMFE, Pavel H, Eigil F, et al. Renal sympathetic denervation in patients with treatment-resistant hypertension after witnessed intake of medication before qualifying ambulatory blood pressure. Hypertension. 2013;62(3):526-532.

29. JUNG, Oliver et al. Resistant hypertension? Assessment of adherence by toxicological urine analysis. Journal of Hypertension. 2013;31(4):766774 .

30. Whelton PK, Robert MC, Wilbert SA, et al. 2017 ACC/AHA/AAPA/ ABC/ACPM/AGS/APhA/ASH/ASPC/NMA/PCNA Guideline for the prevention, detection, evaluation, and management of high blood pressure in adults. Journal of The American College Of Cardiology. 2018;71(19):127-248.

31. Parati G, Lombardi C, Hedner J, et al. Gianfranco et al. Position paper on the management of patients with obstructive sleep apnea and hypertension. Journal Of Hypertension. 2012;30(4):633-646.

32. Fletcher EC. Sympathetic over activity in the etiology of hypertension of obstructive sleep apnea. Sleep. 2003;26(1):15-19.

33. Goodfriend TL, Calhoun DA. Resistant hypertension, obesity, sleep apnea, and aldosterone. Hypertension. 2004;43(3):518-524.

34. Ip MS, Tse HF, Lam B. et al. Endothelial function in obstructive sleep apnea and response to treatment. American Journal of Respiratory and Critical Care Medicine. 2004;169(3):348-353.

35. Rimoldi SF, Scherrer U, Messerli FH. Secondary arterial hypertension: when, who, and how to screen?. European Heart Journal. 2014; $14 ; 35(19): 1245-1254$.

36. Johns MW. A new method for measuring daytime sleepiness: the epworth sleepiness scale. Sleep. 1991;14(6):540-545.

37. ThurnheerR, Bloch KE, Laube I, et al. Respiratory polygraphy in sleep apnoea diagnosis. report of the swiss respiratory polygraphy registry and systematic review of the literature. Swiss Med Wkly. 2007;137(5-6):97102.

38. Garovic VD, Textor SC. Renovascular hypertension and ischemic nephropathy. Circulation. 2005;112(9):1362-1374. 
39. MVB Malachias, WKSB Souza, FL Plavnik, et al. Capítulo 2 - Diagnóstico e Classificação. Arquivos Brasileiros de Cardiologia. 2016;107(3):7-13.

40. Slovut DP, Olin JW. Fibromuscular dysplasia. New England Journal of Medicine. 2004;350(18):1862-1871,

41. Mattsson C, Young WF. Primary aldosteronism: diagnostic and treatment strategies. Nature Clinical Practice Nephrology. 2006;2(4):198-208.

42. Funder JW, Carey RM, Mantero F. et al. The management of primary aldosteronism: case detection, diagnosis, and treatment. The Journal of Clinical Endocrinology \& Metabolism. 2016;101(5):1889-1916.

43. Mulatero P, Stowasser M, Loh KC, et al. Increased diagnosis of primary aldosteronism, including surgically correctable forms, in centers from five continents. The Journal of Clinical Endocrinology \& Metabolism. 2004;89(3):1045-1050.

44. Montori VM, Young WF. Use of plasma aldosterone concentrationto-plasma renin activity ratio as a screening test for primary aldosteronism. Endocrinol Metab Clin North Am. 2002;31(3):619-632.

45. Funder JW, Carey RM, Fardella C, et al. Case detection, diagnosis, and treatment of patients with primary aldosteronism: an endocrine society clinical practice guideline. J Clin Endocrinol Metab. 2008;93(9):32663281 .
46. Arar MY, Hogg RJ, Arant BS, et al. Etiology of sustained hypertension in children in the Southwestern United States. PediatrNephrol. 1994;8:186-189.

47. Hall JE. The kidney, hypertension and obesity. Hypertension. 2003;41(3):625-633.

48. Kidney disease: improving global outcomes (KDIGO) Blood pressure work group. KDIGO clinical practice guideline for the management of blood pressure in chronic kidney disease. Kidney Int Suppl. 2012;2:337414.

49. Cuspidi C, Macca G, Sampieri L, et al. High prevalence of cardiac and extracardiac target organ damage in refractory hypertension. $J$ Hypertens. 2001;19(11):2063-200.

50. Daugherty SL, Powers JD, Magid DJ. et al. Incidence and prognosis of resistant hypertension in hypertensive patients. Circulation. 2012;125(13):1635-1642.

51. Isaksson H, Ostergren J. Prognosis in therapy-resistant hypertension. J Intern Med 1994;236(6):643-649.

52. Pierdomenico SD, Lapenna D, Bucci A, et al. Cardiovascular outcome in treated hypertensive patients with responder, masked, false resistant, and true resistant hypertension. American Journal of Hypertension. 2005;18(11):1422-1428. 